\title{
ADOLESCENTS' EXPERIENCE OF A PARENTAL TRAUMATIC BRAIN INJURY
}

\section{Harris}

MSc (Clinical Psychology)

Masters student, Department of Psychology, University of Johannesburg

\author{
AD Stuart \\ D Litt et Phil \\ Chairperson, Department of Psychology, University of Johannesburg \\ Corresponding author: astuart@uj.ac.za
}

Keywords: traumatic brain injury; consequences; family; adolescence; phenomenology; coping

\begin{abstract}
This study explores the experiences of four adolescents, each living with a parent who has sustained a traumatic brain injury, against the theoretical backdrop of existential-phenomenological psychology. In-depth interviews were conducted and analysed within the context of the existential phenomenology, in an attempt to gain a deep understanding of the psychologically complex themes and patterns embedded in the experience. The phenomenon of parental traumatic brain injury was characterised by denial, anger, grief, guilt, anxiety, over-protectiveness, social isolation, and change in many areas of the participants' lives. The adolescents coped using both approaches and avoidance styles of coping. Religion was a theme in the lives of all four adolescents. Despite the professed negative impact of the experience of having a traumatically brain-injured parent, the adolescents in the current study managed to find some degree of positive meaning in having to cope with such a traumatic event and its consequences. The results are interpreted within an existential-phenomenological psychology framework.
\end{abstract}

\section{ABSTRAK}

Hierdie navorsing verken die belewenisse van vier adolessente wat saam met ' $n$ ouer wat ' $n$ traumatiese breinbesering opgedoen het, leef. Die eksistensieel-fenomenologiese sielkunde word as teoretiese raamwerk gebruik. In 'n poging om 'n diepgaande begrip te verkry van die sielkundig-komplekse temas en patrone wat met die ervaring saamgaan, is indiepte onderhoude binne die konteks van die eksistensieel-fenomenologiese sielkunde gevoer en geanaliseer. Die fenomeen van ouerlike traumatiese breinbesering word gekenmerk deur ontkenning, woede, hartseer, skuldgevoelens, angs, oorbeskerming, sosiale isolasie en veranderinge op baie vlakke van die deelnemers se lewens. Die adolessente het sowel toenadering-as vermydinghanteringstyle gebruik. Godsdiens was ' $n$ tema in die lewens van al vier adolessente. Ten spyte van die beweerde negatiewe impak van die ervaring om ' $n$ breinbeseerde ouer te hê, het die adolessente in die huidige studie daarin geslaag om tog positiewe betekenis in die ervaring van so 'n traumatiese gebeurtenis en die gevolge daarvan te vind. Die teoretiese raamwerk van die studie word gebruik om die resultate te interpreteer. 


\section{INTRODUCTION}

In the 1980's research indicated an estimated incidence of traumatic brain injury in Johannesburg of approximately 316 of every 100000 people per year (Nell \& Brown, 1991:289-296). In developed countries (United States of America, Australia, and the United Kingdom) the incidence, though still high, is significantly lower than in South Africa, at approximately 250 per 100000 (Rose \& Johnson, 1996:i-iv). Motor vehicle accidents accounted for over half of South Africa's brain injuries at that time; other major causes were interpersonal violence and falls (Nell \& Brown, 1991:289-296). These figures may have since changed, however, current statistics are not available. To compound the issue of its high brain injury incidence, South Africa's medical and rehabilitation services are not readily accessible to the majority of its population, due to economic difficulties.

As medical technology and procedures continue to improve, traumatically brain injured persons who previously would not have lived through their injuries are managing to survive; the consequences of a traumatic brain injury can however be vast and pervasive. The physical and cognitive consequences of traumatic brain injury are well recognised (Lezak, 1988:111-123). Perhaps though, the most devastating to family and friends are deficits related to executive functioning. Head injured persons are often reported as being unmotivated, disorganised, inflexible, and unable to self-regulate their behaviour (Port, Willmott \& Charlton, 2002:277-289). Often there are dramatic changes in personality, and emotions can become erratic or seemingly non-existent (Lezak, 1988:111-123). A traumatic brain injury (TBI), with its sudden onset and the inherent uncertainty regarding recovery and rehabilitation, can have a devastating effect on the family as a whole, and upon its individual members.

Research on the familial effects of a member's traumatic brain injury portrays a bleak image of the family in the aftermath of TBI, and for years afterwards. Grief, anger, guilt, blame, loneliness, depression, and isolation are often reported in the literature (Boyle \& Haines, 2002:415-425; Levor \& Jansen, 2000:193-201; MacFarlane, 1999:13-29; Sander, Caroselli, High, Becker, Neese \& Scheibel, 2002:649-657). The majority of available literature focuses mainly on the primary caregiver, usually the spouse of the TBI person, or the parent of a TBI child.

Limited research has been conducted regarding the psychological effects on the offspring of parents who sustain traumatic brain injuries (Ducharme, Davidson, \& Rushford, 2002:241-249; Kreutzer, Gervasio, \& Camplair, 1994:197-210; Macfarlane, 1999:13-29). Surely, children and adolescents will feel the effects of a parent's brain injury differently than a spouse would. However the actual experience as perceived by the offspring has been neglected in research thus far. The research question for the present research follows from the above, namely: How does the offspring of a parent who sustained a traumatic brain injury experience the situation?

The aim of the study was to investigate the experience of adolescents with a brain injured parent, within the framework of an existential-phenomenological methodology. The main premise of existentialism is that a person is free to decide one's own life in one's quest for identity, but that this freedom also entails responsibility for one's decisions (Brennan, 1998:298-312). This movement focuses on the individual "in quest of identity, values and authenticity” (Brennan, 1998:305).

Phenomenology gives methodological direction to the philosophy. The original Greek word for phenomenology means 'to reveal itself'. In contrast to Wundt's (1832 -1920) phenomenology, which studied the elements composing consciousness, existential phenomenology concen-trates on the study of phenomena as experienced by the individual. Existential Phenomenology as a research methodology seeks to observe one's Lebenswelt (lifeworld), to understand and to make known what is seen, all the while remaining true to the facts as they are happening (Brennan, 1998:289-312; Byrne, 2001:830-833). Edmund Husserl (1859-1938) is widely recognised as the founder of modern phenomenology. Martin Heidegger (1889-1976) expanded on Husserl's interpretations of phenomenology to include descriptions of characteristic modes of a person's being-inthe-world (Dasein).

Existentialism gave philosophical substance to Existential-Phenomenological Psychology, which is the application of philosophical principles and phenomenological methodology in the therapeutic and clinical environment, as in the present study. The psychologist, 
Binswanger (1881-1966), believed that the therapist must apprehend the world of the patient as it is experienced by the patient (for example, his/her thought processes, fears, anxieties and social relations). He termed his approach daseins-analyse (analysis of being) (Brennan, 1998:304; Owen, 1994:261-274). Binswanger is furthermore credited for describing the three modes of being-in-the-world namely Eigenwelt, Mitwelt and Umwelt. He also introduced the existential principle of facticity of life or the thrownness of existence, using the term Geworfenheit. These terms are explicated below, within the context of the study.

With respect to the current study, it was thought that adolescents, being in a time of transition between childhood and adulthood, would experience the effects of a parental brain injury differently than younger children or adults within the family. Viewed from a perspective of existential-phenomenological psychology, adolescents as beings-in-the-world, experience a time where changes occur within the Eigenwelt, one's relationship with the self, the Mitwelt, one's connection to his/her individual environment, and the Umwelt, one's relationship with the greater community (Chessick, 1997:117140). Adolescents must develop a self-concept incorporating Geworfenheit, or the limits (such as biological, genetic, familial, or societal limitations) imposed on their freedom to make choices. The existential-phenomenological approach employed as the research methodology allowed for a rich, in-depth understanding of the adolescents as beings-in-the-world interpreting their own experiences of having a traumatically braininjured parent.

\section{METHOD}

\section{Participants}

The participants for this investigation were sourced from Headway Gauteng, a support organisation for head injured persons and their families. The adolescent participants all had a parent (a father in all cases) who had sustained a traumatic brain injury. In addition, the following criteria had to be met to be considered for participation: (1) participants had to be able to clearly remember their TBI parent as he/she was prior to injury, (2) participants had to be residing with the TBI parent at the time of participation, and (3) participants had to feel comfortable conducting the interview in English as it was felt that the use of translators would have negatively affected the phenomenological qualities of the interview.

Four participants were included in the intensive data analysis, description and interpretation required of phenomenological investigations. It is noteworthy that three had not received any counseling or therapeutic intervention following their father's brain injury; one had seen a psychologist briefly but did not consider the experience to have been helpful.

Thabo, Sipho, Katie and Joanna (pseudonyms) were $19,18,18$ and 17 years old, respectively, at the time of the interviews. The elapsed time since their fathers' injuries varied from approximately one and a half to seven years. It was thought that after a year of living with a brain-injured parent, the adolescents would have enough insight into how their lives had changed; the permanence of many of the repercussions from a brain injury negated the need for an upper limit on the period of time elapsed since the injury. With regards to language, Thabo's mother tongue was Tswana and Sipho's was Sotho; both were comfortable conversing in English. Katie and Joanna were both English-speaking. The TBI's sustained were all severe according to Glasgow Coma Scale (GCS) and Posttraumatic Amnesia (PTA) classifications; three of the survivors had been in motor vehicles that collided with other vehicles, and one was cycling when he was hit by a car. All of these men were attending Headway on a regular basis.

\section{Procedure}

The qualitative interviewing technique used for the present study was of a semi-structured nature. Given the emotionally sensitive subject matter being studied, careful ethical considerations were applied: the researcher, a clinical psychologist-in-training under supervision of a registered psychologist, took the stance of being respectful, empathetic and warm throughout the procedure, with the intention of providing a therapeutic space to the participant. The participants had all had brief contact with the researcher prior to being invited into the study. Anonymity was ensured as was the fact that participants were allowed to withdraw from the study at any time. The adolescents were informed with regards to the nature and procedure, and were left to make the decision as to whether they wanted to 
participate or not. The participants were emotionally contained by the researcher prior to ending the session, and were provided with the researcher's contact details in case they required further support. Based on the ethical considerations as explained above, ethical clearance was granted by the university.

The phenomenological approach aims to observe and to understand a phenomenon with the idea that it is meaningful only through people's interpretations of it. This qualitative approach is unique in its ability to access and validate the rich, emotional lifeworld of the individual, and to gain a deep, novel understanding of the phenomenon from which innovative empirical research ideas can be derived.

Access to the lived experience of the participants was achieved via a non-directive (non-structured) approach. This allowed for greater flexibility as the participants were able to respond to questions as they wished to, elaborating where they felt they needed to and addressing feelings or thoughts that may not have been attended to if the interviewer had asked more structured questions. Consequently, the length of the interviews were self-determined, and ranged from approximately 45 minutes to nearly two hours in length. Sufficient information was obtained from the four participants from diverse backgrounds to allow for phenomenological analyses of themes as described below. The interviews were recorded, with the participants' verbal permission, using an audiotape recorder to allow the interviewer to concentrate on the nonverbal communication during the interview. The interviewer discreetly made notes of gestures, facial expressions and other body language during the interview that was added to the linguistic data during the transcription phase. Interviews were analysed via the steps outlined below, in accordance with accepted phenomenological research guidelines (Byrne, 2001:830-833; Kleiman, 2004:7-20).

\section{Step 1: Obtain an intuitive and holistic sense of the data}

Interview transcripts are read through in their entirety to get a sense of the meaning. During this initial reading, the researcher must bracket (set aside) his/her own preconceptions and judgments in order to maintain a maximum openness to the description at hand.

\section{Step 2: Discriminate natural meaning units (NMUs)}

The researcher re-reads the data, breaking them down into naturally occurring units that spontaneously transpire from the data. This breakdown into natural meaning units is done by recording each time a change in meaning is perceived, based on the participant's stated experience of the phenomenon of investigation. The intention communicated by each NMU is then reduced as succinctly and as correctly as possible; to ensure accuracy it is helpful to use the participant's own words where possible. Although the data are separated into distinct units, it remains important to bear their relatedness in mind.

\section{Step 3: Develop a constituent profile description}

Having listed the NMU's in step two, the researcher then can eliminate those that are redundant. Because the determination of irrelevance can be rather subjective, only those units that are of blatant irrelevance should be discarded. From the remaining units, the researcher constructs a constituent profile description, a condensed summary of the original data, which contains the essence of the experience of the participant as expressed by the participant.

\section{Step 4: Develop a second order profile}

During this phase, the researcher repeats steps one through three, but on the constituent profile description. Data are checked to ensure no repetitions and the profile is reconstituted based on any further eliminations.

\section{Step 5: Perform a hierarchical cate- gorisation}

NMUs with similar but not identical meanings are placed into categories, which are then arranged in a hierarchical fashion to facilitate the remaining steps in analysis.

\section{Step 6: Write an extended description of categories \\ Based on the examination of the categories, the re- searcher is able to write an extended description of how the participant has experienced the phenomenon in general. Thus, by this phase the researcher has elicit- ed the essence of the phenomenon as experienced by the participant.}




\section{Trustworthiness}

The language of reliability and validity was originally developed for use in quantitative science and signify adherence to a positivist reality which is not applicable to existential theoretical frameworks. The issue of repeatability and trustworthiness is however crucial to the acceptance of the research methods employed by phenomenologists working in the existentialist tradition (Von Eckartsberg, 1989:3-20). The aim of phenomenology is not to provide idiosyncratic descriptions of phenomena but rather to use these descriptions of experience as basis for discovering commonalities that depict the core of a phenomenon (experience) (Seamon, 2000:157-178). In the present research the commonalities in the experience of adolescents of a parental brain injury, discovered through the phenomenological (non-directive, non-structured) interviews described above, depict the core of their experience (see thematic discussion). According to Seamon (2000:157-178), reliability can only be obtained by what he calls intersubjective corroboration, in other words, can other persons find in their own lives, be it directly or vicariously, what phenomenologists describe in their work. It is believed that this is true of the present study. Furthermore, emerging themes were frequently validated with the participants themselves. De Witt and Ploeg (2006:215-229) furthermore maintain that the rigour of phenomenological research can be evaluated by judging its balanced integration of philosophical concepts in the study methods and findings, as well as a balance between the voices of the participants and the philosophical explanation. In the present study the philosophical concepts, study method and findings ('voices of the participants') are fully integrated below, in the discussion of findings. Furthermore openness, which is a systematic, explicit process of accounting for the multiple decisions made throughout the study; concreteness, which relates to the usefulness for practice of study findings; resonance, which encompasses the felt effect of reading the study findings upon the reader; and actualisation, which refers to the future realisation of the resonance of study findings, would all help to preserve the integrity and legitimacy of phenomenological research (De Witt \& Ploeg, 2006:215-229). Judgment of this rigour remains subjective, but it is believed that the present study fully addresses these issues.

\section{FINDINGS AND THEMATIC DISCUSSION}

Phenomenological analysis of the interview transcripts resulted in certain themes that were common to the lifeworlds of these adolescents.

\section{Shock and fright}

Each participant recalled a frightened or shocked reaction to finding out about the accident, although these feelings differed in intensity, duration, and in how long after the injury they were experienced. Joanna, for instance discussed "feeling numb" both immediately after finding out about the accident as well as on a recurring basis for the first few months of her father's recovery. Katie remembered fearing her father because he looked and behaved so differently.

Although this initial reaction is similar to what one experiences following the death of a loved one, adjustment to head injury does not seem to occur in the wellknown linear stages proposed by Kubler-Ross's (1969:1-71) bereavement theory. Rather, stages are skipped altogether, or returned to during different phases of the brain-injured person's recovery. The finality of death differs from a head injury, in which injury effects and expectations of recovery frequently change with time. This has implications for therapists working with adolescents of brain-injured parents.

\section{Coping and adaptation}

The adolescents made various attempts to cope with their fathers' injuries. Their ways of coping changed over time in some instances. Avoidant and emotionfocused coping methods such as anger and denial were initially experienced by all of the participants. Whereas Thabo and Sipho seemed to have moved beyond these methods to more beneficial ways of coping (for example, planning for the future, directly assisting their mothers and siblings), Katie did not seem to have adopted the same problem-focused style of coping. Her predominant emotion was anger. Joanna seemed to be using a combination of both strategies. She still harboured frustration and anger, but she also sought other ways of dealing with her emotions. She went to see a psychologist and, even though she felt it did not help her, it was an attempt at dealing with her emotions directly. 
When their fathers' brain injuries happened, Thabo was 16-years old, Joanna was 15, Sipho was 17 and Katie was 11. Research has shown avoidance responses to be more common in childhood than approach responses (Compas, Banez, Malcarne, \& Worsham, 1991:2324). The anger held during the initial adjustment to the injury is also understandable as a coping mechanism. Yet, both Katie's anger and Joanna's anger, to a certain degree, persisted despite both having reached Piaget's stage of formal operational thought (based on their ages); Sipho and Thabo do not experience much anger about the injury presently and feel in control of their futures and their ability to help their parents. The degree to which a traumatic event creates long-lasting problems has also been shown to affect the successfulness of coping, with long-term problems associated with feelings of hopelessness and non-control. With the nature of a brain injury involving permanent longterm deficits, the associated stress for the adolescents is very high and is perhaps felt stronger and more persistently in girls than in boys. Needless to say, this is all speculation and future research is needed to further investigate gender differences in coping with a parent's brain injury.

For the most part, the adolescents seem to have adapted to their changed family situations since the accident, although there are ongoing issues associated with having a brain-injured father. Fortunately, the adolescents in this study seem to have some degree of cohesion between the non-injured family members that has probably helped them cope more optimally.

\section{Religion}

All of the adolescents thought about the event from a religious or spiritual perspective. Thabo felt that God had played a large role in adapting to his father's injury, but felt alone in his belief in God as people around him denied His existence. Joanna and her family are Catholics and, although Joanna did not agree with many of the Catholic beliefs, she felt that her belief in God had helped her through some of the most difficult times. Katie thought a lot about the role of God in her experience. She remembered feeling anger towards God initially because she could not understand why God would have bestowed this tragedy on her father who "prayed every day". Sipho thought about the meaning of the accident from a Christian perspective ("maybe it's part of God's plan") but also from a more traditional African perspective in terms of "unfinished business" with someone, or having to do with "the ancestors".

Evidently, the adolescents tried making sense of the event by fitting the tragedy into their pre-existing ways of defining the world. It seems as though each of the participants did adhere to religious beliefs prior to the incident and tried to explain the accident to themselves in terms of those beliefs.

\section{Positive meaning-making}

Regardless of religious affiliation, it is notable that each of the participants found some positive meaning in the tragedy. Sipho and Thabo expressed a strong determination and optimism toward the future. Perhaps the most powerful example of salutogenesis (positive meaning making) was Thabo. He had reached such a low stage that he was contemplating suicide but, from this suffering he developed a strong inner strength and "belief in (himself)". Sipho discussed a new perspective where he felt he must "make every second count". He felt incredibly grateful that his father was alive. Katie and Joanna felt they had become stronger since the accident. Katie discussed her greater psychological resilience, seemingly due to having to deal with her father's overt aggressive behaviours. Joanna felt that she was better able to put things in perspective, looking beyond petty problems towards "the bigger things in life".

This positive meaning making was not expected to arise as a theme, given the existing literature that focuses on a wholly negative experience of familial traumatic brain injury.

Antonovsky (1987:6-280) discusses the ability to do well under extreme stress, and to find positive meaning, as being a function of internal factors that promote health and well-being. This sense of coherence is due to (1) comprehensibility, the extent to which people see the situation as predictable, (2) manageability, the extent to which people believe they have the adequate resources to deal with the stress and (3) meaningfulness, the extent to which people find life to be meaningful, and the belief that challenges can be successfully overcome. The adolescents in the current study 
seem to have higher senses of coherence than would be expected given the unpredictable nature of brain injury, and their reported lack of knowledge about brain injury. The cohesiveness of their families and strong attachment with their mothers could have contributed to their feeling of manageability over the situation, hence an improved sense of coherence.

\section{Lack of information provided}

The adolescents all reported not being given enough information about their fathers' injuries. They made various attempts to gain information from medical personnel or from their non-injured parents. Of course, it cannot be said with certainty that information was not provided. The shock and anxiety felt following a tragic event may interfere with memory for relayed information (Paterson, Kieloch \& Gmiterek, 2001:48-53). It is also possible that the young adolescents had difficulty understanding the terminology associated with traumatic brain injury at this stage in their lives.

Thabo would try and ask his mother questions but then would feel guilty about getting her upset, and he just learned to "keep quiet". In Katie's case, the lack of information provided to her seemed to be a function of people trying to protect her. She reported that she "(thought he) would come back to normal". She felt an initial lack of awareness about the seriousness of her father's injury, but looking back realised that her mother was trying to put on a "strong face". Sipho recalled getting information from the health professionals about his father's physical injuries, but not about the brain injury itself. Sipho seemed to lack knowledge (or perhaps it was denial to some extent) about the long-term effects of brain injury and he implied that his father would still "get better". Joanna expressed a lot of anger about her perceived lack of information from health professionals regarding the brain injury: "(They) would not tell us anything", she recalled. Out of the four participants it seemed that Joanna was the most critical about lack of information from the health professionals. From an external perspective, it could be that her anger, frustration, and general lack of trust in the health professionals interfered with the provision and understanding of information regarding her father's injury.

In addition to the perceived lack of information from health professionals, the adolescents also often felt unable to ask for information about their father's injury from their mothers. Generally an adolescent's interaction with medical personnel would be more limited than a spouse's and so they were reliant on information to be provided from their mothers. In such a distressing time, the mothers may have neglected providing their children with information, or simply may have been trying to protect them from additional pain. The adolescents felt that the lack of information contributed to their feelings of worry and anxiety.

\section{Worry and anxiety about family and parentification}

The adolescents reported genuine concern and anxiety about how their non-injured family members were dealing with the situation. All four participants were highly aware of the loss and sadness experienced by their mothers in particular and felt that they took over some of the parental roles, both of their mothers and their brain-injured fathers. Associated with this worry about their mothers was a feeling of guilt for the eventuality that they, themselves, will leave home and their mothers will be left alone with their fathers.

Parentification refers to "a functional and/or emotional role reversal in which the child sacrifices his or her own needs for attention, comfort, and guidance in order to accommodate and care for the logistical or emotional needs of the parent" (Chase, 1999:5). Sipho and Thabo seemed to have the desire to fill their fathers' former roles as breadwinner. Sipho, Thabo, and Joanna adopted many parental-type roles involving personal hygiene, feeding, entertaining, and the taking over of personal chores that the injured parent used to do. Joanna often came across as a bit condescending when speaking about her father, almost referring to him in the manner one would a small child. She also speaks of wanting to protect him from potential embarrassment. Katie however does not seem to have been parentified at all; perhaps her extreme anger towards her father obstructs any possible parentified behaviours.

\section{Loneliness and isolation of themselves and the family}

Common to the participants was a sense of being alone and isolated, often due to the perceptions that others did not understand the situation, or their feelings about 
the situation, or simply that they preferred not to discuss their feelings with their friends.

Both Joanna and Thabo were honest about the fact that they often wanted friends to talk to but that they simultaneously tended to push their friends away. In Thabo's case this was due to his anger and aggression. He felt that his friends rejected him and that they did not want to associate with him because his father was "abnormal". Joanna reported not allowing people to get close to her, as an emotional protective mechanism. In a sense Thabo's and Joanna's experience of feeling alone represented a self fulfilling prophecy, where they told themselves that their friends did not understand, and thus made little or no effort to help them understand, nor any positive response when the friends initiated contact. Essentially, their own actions seemed to further isolate them from their peers.

Although Katie discussed feeling isolated from her friends, she reported meeting a new group of friends about a year after the accident with whom she was able to talk; she felt that her anger then subsided a bit. Her anger perhaps could have been partially a reaction to loneliness that was not consciously recognised by her at the time.

Not only was there a sense of individual isolation for the adolescents, but a recognition that their families also tended to socialise less with people than they did before the accident. As is often the case, there was support from family and friends immediately after the accident, but it waned following the initial crisis stage, and when the permanence of the changes associated with the brain injury were understood (particularly those changes related to personality).

It would seem that the sense of being alone and isolated was felt most strongly a little while after their fathers' injuries. Social isolation is a common experience following a family's brain injury and is well supported by the literature (Kay \& Lezak, 1990:22-65; Kozloff, 1987:14-23). That the adolescents were most troubled by the rejection and isolation they felt from their peers is understandable since young people place increasing importance in their friendships during adolescence and describe their peer relationships as the most important element in their lives (Chase,1999:333).
The adolescents in the current study managed, however, to strengthen relationships with the non-injured parent and with siblings in the family. This support likely played a helpful role in the participants' adaptation.

\section{Changes in family relationships}

A pervasive theme in the lives of all four participants was change. In addition to drastic changes in their fathers, there had been changes in other family relationships. Although there were physical consequences to their fathers' accidents, the most disruptive and difficult changes were those related to personality, which changed the father to offspring relationship.

Thabo and Sipho both found that their fathers were less intimidating, and gentler than their former selves. Although they both still had a lot of respect for their fathers, no longer did they think of their fathers as being in the role of a disciplinarian. Katie remained frightened and angered by her father's aggression and his violent temper that emerged following the injury. Joanna felt that her father had gone from being a man who was competent in whatever he did to a dependent child-like man, whom she could not think of as a father in any way.

Due to the immense changes in their fathers, the adolescents experienced a profound sense of loss of the father they knew. Joanna felt that a part of her had been torn away and was "never coming back". Katie also described her post-injury father as a completely different man than he was before. In all instances, the adolescents no longer viewed their fathers as fulfilling the same fatherly, authoritative role as prior to the accident. This may be due to the fact that, in all cases, the fathers had to surrender their independence to various degrees, and now relied on their adolescent children to assist them.

As mentioned previously, the adolescents all held a deep understanding and sensitivity towards the impact their fathers' injuries had on their mothers. As a result, the participants generally felt that they were closer to their mothers due to a mutual dependence for support. The participants seemed to spend more time with their mothers since the accident, often helping with tasks associated with caring for their fathers. Joanna reported 
not being "that close" to her mother prior to the accident and, even though she felt her mother was not paying attention to her following the accident, she reported having a better, more supportive relationship with her mother.

With the exception of Joanna who is an only child, all of the participants reported being somewhat closer to their siblings than they were prior to the accident. Katie, in particular, seemed very distressed by her older sister's sadness following the accident. One had the sense that Katie felt her older sister was more vulnerable than herself, perhaps due to her deafness, and Katie thus seemed to try protect her sister from her father's anger. She reported being closer to her sister, despite the physical distance between them (her sister resides in the UK) since the accident. Sipho reported feeling closer to all three of his siblings, even though he had taken on a more fatherly role with respect to his younger siblings as he "(spent) more time helping (them) with their homework". His older sister was the person he felt most able to discuss his feelings with.

\section{Changes in self}

The changes the adolescents experienced of themselves seem to be related to the increase in responsibilities, changes in family roles and expectations, and the search for meaning following their fathers' brain injuries. The adolescents seemed to have been forced to mature faster than their peers.

It also seemed that the participants had thought quite seriously about their futures. They all felt differently about their future plans than they did prior to the accident. Both Sipho and Thabo felt very responsible for looking after their families. Whether this is a function of gender or culture is uncertain but it is interesting that neither Joanna nor Katie reported feeling directly responsible for looking after their parents in the future. Katie reported wanting to travel following graduation but was experiencing some guilt about leaving her mother alone with her father. Joanna wanted to use the experience to help others.

Whether the emotional maturation that occurred over time in the adolescent was a result of his/her experience of parental head injury or simply a factor of elapsed time and age is a matter of speculation, but one had a sense that the parental brain injury had accelerated the adolescents' maturation process.

\section{The role of culture and ethnicity}

It is acknowledged that a study with such a small sample size cannot make assumptions or judgments based solely on its findings. Still, the possible cultural differences noted in this study are interesting to review. Both of the males (Thabo and Sipho) were Black South Africans and both at a socioeconomic level lower than the two White females (Joanna and Katie). Many of the beliefs about brain injury that were found in Mokhosi and Grieve's (2004:301-317) study on brain injured people and their families living in rural African communities were not held by Thabo or Sipho, both having been raised in more Westernised communities. Sipho did, however, make mention of "unfinished business" and "the ancestors" as a way of making sense of the injury.

Both Sipho and Thabo seemed to uphold the standards of a more traditional, collectivist society in terms of the great deal of respect felt for their parents, and the practice of supporting their elders. Neither Sipho nor Thabo gave any indication of resentment or ill feelings about having to care for their fathers. Both made comments around the idea of wanting to help their fathers the way their fathers helped them, and of determination to succeed in their futures so they could be of financial assistance to their parents. With Katie and Joanna, the care they provided for their fathers was seen as much more of an obligation or a burden, and they did not mention making financial provisions for their parents in the future.

Again, it cannot be said with any certainty that the differences between Sipho and Thabo, as a group, and Joanna and Katie, as a group, are due to culture; they could be a function of either gender or socioeconomic status to name just a few possibilities.

\section{DISCUSSION, LIMITATIONS AND RECOM- MENDATIONS}

The phenomenological interviews seemed to be of therapeutic value to the adolescents. The reported isolation and lack of external support reported by the adoles- 
cents appeared somewhat alleviated as a result of the therapeutic alliance. Each participant described a wide range of emotions, feelings, and interpretations of his/ her individual experience, but commonalities between the adolescents' lifeworlds were found. The Eigenwelter of the adolescents were shaped by the experience, seemingly such that they matured faster than their peers and embraced a rather worldly outlook. Within the Mitwelter of the adolescents there were changes in family dynamics, structures, and expectations that reciprocally influenced the families' members. The adolescents' reported isolation and loneliness reflected a lack of balance between the Mitwelt and Umwelt; they felt unable to be a part of the outside world in the ways they were prior to the parental TBI. Furthermore the adolescents were forced to come to terms with their Geworfenheit in several ways: they had to realise that they could not improve their fathers' recovery beyond what was medically feasible, there were new financial limits placed upon the family, and they could not find help for themselves that did not exist on a community level. Furthermore, they were limited in their understanding of the brain injury due to a reported lack of information provided to them. Encouragingly, despite all of these limitations, they managed to find some degree of positive meaning making in the event.

It seems that the adolescents were unique in their interpretation of their experiences. They were able to examine their worlds using an abstract level of processing that would likely not be possible for younger children. They did not exhibit the aggressive, acting out behaviours reported in the literature conducted on younger children. Additionally, their experiences were different to those of the spouses of the injured parent as the adolescents, both simply because of the nature of the different relationships, but also because they felt a sense of responsibility for their parents, and a sense of guilt for abandoning the non-injured parent.

In spite of the insightful findings in the present study, some limitations need to be noted. Firstly, in a phenomenological study, generalisability is compromised in favour of a deep, extremely rich understanding of the topic of investigation. Subsequent empirical studies usually ensue from the phenomenological findings. The researcher, however, was careful to strictly adhere to the existential phenomenological principles and methodology discussed previously. Secondly, the fact that
Headway is a support service for brain-injured persons and their families may mean that the adolescents in this study are supported more than those in the general population of adolescents with brain-injured fathers. Thirdly, it is possible that despite all attempts to remain unbiased, some influence was still exerted over the direction the interviews took, as well as in the interpretations of gestures, language, and emotions portrayed by the participants.

Based on the essences derived from the current study and issues that arose from the current study, in combination with existing literature, several recommendations can be made that would likely improve the experience of an adolescent whose parent sustains a traumatic brain injury. Firstly, education regarding the nature of head injury and future prognosis should be provided to the adolescent in a way that he/she will understand and in an extremely sensitive and time-appropriate manner. Secondly, a support service catering specifically to adolescents would be helpful in addressing their unique needs following a parental brain injury. In addition to a group support system exclusively for adolescents, the adolescent and his/her family (including the TBI parent, if at all possible) should attend some family therapy sessions.

This phenomenological investigation sought to understand the experiences of two young men and two young women who were forced to deal with the life-altering phenomenon of a parent's TBI. Despite the profound negative implications of their fathers' injuries amidst the already turbulent life phase of adolescence, it is thought truly admirable that the participants exhibited enough strength, courage, and resilience, that they were able to attribute some positive meaning to the experience.

\section{REFERENCES}

ANTONOVSKY, A 1987: Unraveling the mystery of health: How people manage stress and stay well. San Francisco: JosseyBass.

BOYLE, GJ \& HAINES, S 2002: Severe traumatic brain injury: Some effects on family caregivers'. Psychological Reports, 90:415-425

BRENNAN, JF 1998: History and systems of psychology; $5^{\text {th }}$ edition. New Jersey: Prentice Hall.

BYRNE, M 2001: Understanding life experiences through a phe- 
nomenological approach to research. Association of Operating Room Nurses Journal, 73(4):830-833.

CHASE, ND 1999: Parentification: An overview of theory, research and societal issues. (In: Chase, ND ed. 1999: Burdened children: Theory, research and treatment of parentification. Thousand Oaks: Sage, pp 3-33.)

CHESSICK, RD 1997: Phenomenology in psychiatry and psychoanalysis. American Journal of Psychoanalysis, 57(2):117140.

COMPAS, BE; BANEZ, G; MALCARNE, V \& WORSHAM, N 1991: Perceived control and coping with stress: A developmental perspective. Journal of Social Issues, 47:23-24.

DE WITT, L \& PLOEG, J 2006: Critical appraisal of rigour in interpretive phenomenological nursing research. Journal of Advanced Nursing, 55(2):215-229.

DUCHARME, JM; DAVIDSON, A\& RUSHFORD, N 2002: Treatment of oppositional behaviour in children of parents with brain injury and chronic pain. Journal of Emotional and Behavioural Disorders, 10(4):241-249.

KAY, T \& LEZAK, M 1990: The nature of head injury. (In: Corthell, D ed. 1990: Traumatic brain injury and vocational rehabilitation. Menomonie, Wisconsin: Stout Vocational Rehabilitation Institute, pp 22-65.)

KLEIMAN, S 2004: Phenomenology: To wonder and search for meanings. Nurse Researcher, 11(4):7-20.

KOZLOFF, R 1987: Networks of social support and the outcome of severe head injury. Journal of Head Trauma Rehabilitation, 2(3):14-23.

KREUTZER, JS; GERVASIO, AH \& CAMPLAIR, PS 1994: Primary caregivers' psychological status and family functioning after traumatic brain injury. Brain Injury, 8(3):197-210.

KUBLER-ROSS, E 1969: On death and dying. London: Tavistock. LEVOR, KD \& JANSEN, P 2000: The traumatic onset of disabling injury in a marriage partner: Self-reports of the experience by able-bodied spouses. Social Work, 36(2):193-201.

LEZAK, MD 1988: Brain damage is a family affair. Journal of Clinical and Experimental Neuropsychology, 10(1):111-123. MACFARLANE, M 1999: Treating brain-injured clients and their families. Family Therapy, 26(1):13-29.

MOKHOSI, MT \& GRIEVE, KW 2004: African families perceptions of traumatic brain injury. South African Journal of Psychology, 34(2):301-317.

NELL, V \& BROWN, DSO 1991: Epidemiology of traumatic brain injury in Johannesburg: Morbidity, mortality and etiology. Social Science and Medicine, 33(3):289-296.

OWEN, IR 1994: Introducing an existential-phenomenological approach: Basic phenomenological theory and research - Part 1. Counselling Psychology Quarterly, 7(3):261-274.

PATERSON, B; KIELOCH, B \& GMITEREK, J 2001: ‘They never told us anything': Postdischarge instruction for families of persons with brain injuries. Rehabilitation Nursing, 26(2):48-53.

PORT, A; WILLMOTT, C \& CHARLTON, J 2002: Self-awareness following traumatic brain injury and implications for rehabilitation. Brain Injury, 16(4):277-289.

ROSE, FD \& JOHNSON, DA Eds. 1996: Brain injury and after: Towards improved outcome. West Sussex: John Wiley. SANDER, AM; CAROSELLI, JS; HIGH JR, WM; BECKER, C; NEESE, L \& SCHEIBEL, R 2002: Relationships of family functioning to progress in a post-acute rehabilitation programme following traumatic brain injury. Brain Injury, 16(8):649-657.

SEAMON, D 2000: A way of seeing people and place: Phenomenology in environment-behaviour research. (In: S Wapner; J Demick; T Yamamoto \& H Minami (Eds.) 2000: Theoretical perspectives in environment-behavior research. New York: Plenum, pp 157-178).

VON ECKARTSBERG, R 1998: Introducing existential- phenomenological psychology. (In: R Valle (Ed.) 1998: Phenomenological inquiry in psychology. New York: Plenum, pp 3-20). 